\title{
Brazilian researcher, Annual Meeting and the BOR Journal: pillars of the SBPqO
}

Giuseppe Alexandre Romito

President of the SBPqO (2010-2012) t is with great honor that I commence my 2-year term as President of the Sociedade Brasileira de Pesquisa Odontológica (SBPqO) - the Brazilian Division of the IADR. For 27 years dental researchers and others from related areas have contributed to strengthening and expanding our area of knowledge. When we first started, only a few studies were submitted to be presented at our meetings; today this number has leaped to an average of 3,000 peer-reviewed research studies submitted every year. Our annual meeting is consolidated, and our Board of Directors and Advisors are, nonetheless, striving to improve it each year. It should be borne in mind that ours is the third or fourth largest IADR Division, depending on which classification criterion is used. Today, Brazilian research is recognized worldwide for its quality and its impact, in all the different areas of dentistry. In Surgery and Orthodontics, Brazil is the greatest producer of scientific articles according to the Scopus database.

In this context, our journal - Brazilian Oral Research (BOR) - should play a leading role in the SBPqO (and in the IADR), as a reflection of the level of success achieved by our annual meetings. Having a lead role in our country's research entails having a communication vehicle that can live up to this standard of success.

Strengthening the BOR is one of the goals of my tenure as President. The journal has evolved year after year, but the pace must be accelerated. Together with our Scientific Editor, Prof. Sigmar M. Rode, PhD, who has spared no pains to improve its quality, we have set down a timetable for specific actions to be taken in the next couple of years: (i) upgrading the BOR starting in 2011, from a quarterly to a bi-monthly publication; (ii) improving the speed and quality of the review process of articles submitted; (iii) encouraging citation of the articles published in the BOR by those researchers publishing papers in other international journals; (iv) publishing one or two special issues annually with systematic and semisystematic literature reviews on specific subjects, together with other scientific associations, such as Aboprev, ABENO and SOBE, among others.

This and other initiatives are designed to gradually increase the BOR's impact factor, thus giving momentum to a virtuous cycle and feed-back process whereby quality papers are submitted continuously. Only in this way will both national and international authors maintain their interest in sending papers to our journal.

I believe that the SBPqO should stand on 3 fundamental pillars: the Brazilian researcher, outstanding annual meetings and a strong official publication. At the end of my term as President, I hope to have contributed toward a new period of success for the Brazilian Oral Research Journal. And I am counting on everyone's contribution! 